\title{
Simulação como Estratégia para o Ensino de Administração em Enfermagem
}

\author{
Valéria Marli Leonello*, Maria Madalena Januário Leite, Denise Maria de Almeida, \\ Cláudia Aparecida Dias \\ Escola de Enfermagem da Universidade de São Paulo \\ * Autora para correspondência: valeria.leonello@usp.br
}

\section{RESUMO}

$\mathrm{Na}$ enfermagem, a simulação pode ser utilizada como um recurso para o ensino de habilidades e atitudes relacionadas a instrumentos gerenciais fundamentais ao trabalho em saúde, entre elas as estratégias de negociação e conflito. Este relato de experiência descreve o uso da simulação como estratégia de ensino na disciplina Administração Aplicada à Enfermagem, do curso de graduação em Enfermagem da Escola de Enfermagem da Universidade de São Paulo (EEUSP). Para realizar a simulação aqui tematizada, foram desenvolvidas estas etapas: construção do roteiro, montagem do cenário, definição dos participantes, desenvolvimento da simulação e debrifieng. A simulação alcançou seu objetivo ao colocar os discentes de Enfermagem próximos de uma situação real, permitindo a reflexão acerca de suas habilidades e atitudes na resolução de conflitos e negociação.

Palavras-chave: Educação em Enfermagem; Educação Superior; Exercício de Simulação.

\begin{abstract}
In nursing, simulation can be used as a strategy for teaching skills and attitudes related to management tools used in health work, among them, negotiation and conflict strategies. This experience report describes the use of simulation as a teaching strategy in the discipline Administration Applied to Nursing of the undergraduate Nursing course of the School of Nursing, Universidade de São Paulo. In order to carry out the simulation, the following steps were developed: building the script, setting the stage, defining the participants, developing the simulation and debugging. The simulation achieved its goal by placing Nursing students close to a real situation allowing them to reflect on their abilities and attitudes in conflict resolution and negotiation.
\end{abstract}

Keywords: Nursing Education; Education, Higher; Simulation Exercise.

\section{Introdução}

O ensino por simulação é considerado uma estratégia que promove a aproximação do aluno com uma situação de trabalho, por meio de um ambiente simulado, planejado e sistematicamente orientado para o aprendizado e a participação ativa do aluno (BLAND et al., 2011).

Na área de saúde, a simulação é uma estratégia usada tradicionalmente para desenvolver habilidades clínicas e instrumentais. Entretanto, também é possível utilizá-la para o ensino de habilidades e atitudes relacionadas com instrumentos gerenciais, como as estratégias de negociação e conflito.

As situações de conflito fazem parte de qualquer equipe de trabalho. $\mathrm{Na}$ área de saúde, o profissional de enfermagem, ao gerenciar o trabalho da equipe de saúde, articulando-se e se comunicando com um conjunto de pessoas, vivencia diferentes situações de conflito. Identificar os tipos de conflito e desenvolver habilidades e atitudes que propiciem a utilização de diferentes estratégias de negociação são, portanto, fundamentais para o desenvolvimento de seu trabalho.

Promover o ensino dessa temática por meio da simulação oportuniza a vivência em cenários de conflito muito próximos da realidade dos serviços de saúde, de forma segura e sistematizada para o aluno de enfermagem.

Então, apresenta-se aqui o relato de uma experiência de utilização da simulação como estratégia 
de ensino, realizada na disciplina Administração Aplicada à Enfermagem, do curso de graduação em Enfermagem da Escola de Enfermagem da Universidade de São Paulo.

A simulação teve como tema "Conflito e Negociação na Enfermagem" e os objetivos foram: identificar o conflito como parte inerente do processo de trabalho em saúde, conhecer as estratégias para o enfrentamento de conflitos, identificar as etapas do processo de negociação e refletir sobre os principais desafios do gerenciamento de conflito e do processo de negociação.

\section{Metodologia e Desenvolvimento}

Foram desenvolvidas as etapas para realizar-se a simulação, segundo os fundamentos e experiências já expostos por Araújo e Quilici (2012). Na Figura 1, apresentamos a operacionalização da experiência no cenário de prática dos educadores:

\section{Resultados e Discussão}

Observou-se que cada grupo desenvolveu a discussão de forma distinta, o que resultou em um debate ampliado e aprofundado sobre o tema. Por meio da problematização e resgate da cena, estimulou-se a reflexão, possibilitando aos alunos projetar-se em direção ao futuro exercício profissional. Estudos mostram que a utilização da simulação permite a mobilização dos domínios cognitivo, psicomotor e afetivo para a abordagem de situações complexas, favorecendo a aplicação do conhecimento na futura prática profissional dos alunos (TEIXEIRA \& FELIX, 2011).

Destaca-se o papel do professor, como mediador da discussão em cada grupo, propiciando a articulação entre a discussão e o referencial teórico sobre o tema abordado. Na discussão, o docente encoraja os alunos a explorarem suas emoções e a reconhecerem suas necessidades de aprendizagem, promovendo um ambiente favorável à assimilação

\begin{tabular}{|c|c|}
\hline Local & $\begin{array}{l}\text { - A simulação foi realizada no Centro de Laboratórios de Enfermagem em Ensino, } \\
\text { Habilidades, Simulação e Pesquisa - CELAB-EEUSP. }\end{array}$ \\
\hline Público & - 80 estudantes, divididos em 4 grupos de 20 alunos. \\
\hline Duração & $\begin{array}{l}\text { - } 3 \text { horas, sendo: } \\
\text { - 20' para a construção do cenário e orientação dos alunos; } \\
\text { - } 40 \text { ' para o desenvolvimento (uma simulação de 10' para cada grupo formado); } \\
\text { - } 2 \text { horas para o debriefing. }\end{array}$ \\
\hline Roteiro & $\begin{array}{l}\text {-Uma situação de conflito vivenciada por uma equipe de enfermagem em um } \\
\text { hospital. }\end{array}$ \\
\hline Cenário & $\begin{array}{l}\text { - Posto de enfermagem. Uma sala com uma mesa e três cadeiras. Formulários e } \\
\text { materiais de mesa. }\end{array}$ \\
\hline Participantes & $\begin{array}{l}\text { - Uma auxiliar de enfermagem (AE), uma enfermeira de unidade (E) e uma } \\
\text { enfermeira coordenadora de unidade (EC). Para representar o papel dos } \\
\text { personagens, duas tutoras da disciplina encenaram o papel da AE e da E. O papel } \\
\text { da EC foi representado por alunas de enfermagem convidadas a participar da } \\
\text { cena. }\end{array}$ \\
\hline Desenvolvimento & $\begin{array}{l}\text { - A cena mostrou uma situação de conflito entre as personagens, que agiam de } \\
\text { formas bem distintas com relação ao conflito e à negociação. }\end{array}$ \\
\hline Debriefing & $\begin{array}{l}\text { - Cada grupo realizou a discussão com base em questões relacionadas com a cena } \\
\text { e o tema proposto. Todos os grupos foram acompanhados pelo professor, que } \\
\text { mediou a discussão e fez a articulação com o referencial teórico associado ao } \\
\text { tema. Ao final, cada grupo, com a colaboração do mediador, fez uma síntese dos } \\
\text { principais aspectos abordados. }\end{array}$ \\
\hline
\end{tabular}

Figura 1 - Etapas para a realização da simulação ora relatada, São Paulo, 2015. 
e à consolidação do conhecimento, facilitando a interação entre os atores para explorarem, analisarem e compreenderem as ações desenvolvidas quanto aos processos de pensamento e emoções vivenciadas (OLIVEIRA, PRADO \& 2014; MEAKIM et al., 2013).

Além disso, a participação das alunas como enfermeiras coordenadoras de unidade conferiu um papel ativo às discentes. Como metodologia ativa de ensino-aprendizagem, a simulação favorece ao aluno o protagonismo, promovendo o aprimoramento de seu desempenho teórico-prático (ARAÚJO \& QUILICI, 2012). A percepção dos graduandos é favorável ao uso da estratégia antes e durante os estágios curriculares porque permite que esses sejam colocados diante de situações-problema próprias da prática profissional, que demandam a mobilização de conhecimentos prévios e estimulam o raciocínio crítico (VALADARES \& MAGRO, 2014).

Ressalta-se um fator limitante, relacionado com a inadequação do espaço físico ao número de alunos, algo que obrigou à repetição da simulação por quatro vezes, gerando variações em cada encenação e, portanto, a necessidade de discussão para cada grupo separadamente. Essas variações foram recuperadas em um momento presencial em sala de aula, com todos os alunos envolvidos na simulação.

Observa-se a importância de recursos humanos adequados para a consecução desta atividade. $\mathrm{Na}$ cena realizada, além da professora responsável, duas alunas do Programa de Aperfeiçoamento ao Ensino (PAE) colaboraram ativamente no planejamento e desenvolvimento da estratégia. $\mathrm{O}$ tempo para o planejamento também é um fator importante, pois a construção do roteiro e do cenário, bem como a elaboração das perguntas norteadoras para a discussão no "Debriefing" demandaram cerca de três horas, ou seja, o mesmo tempo utilizado para a realização da simulação.

Experiências exitosas de uso da simulação em ambientes controlados, como os laboratórios de práticas de enfermagem de instituições de ensino superior, validam essa estratégia pedagógica no ensino de enfermagem, porque demonstram que a tríade realidade simulada, discussão coletiva e reflexão mediada favorece o desenvolvimento de habilidades e competências técnicas dos alunos e tem papel importante referente ao aspecto ético-legal e de segurança do paciente (FIGUEIREDO, 2014).

\section{Conclusões}

A simulação teve seu objetivo atingido ao colocar os discentes de enfermagem próximos de uma situação real, permitindo a eles a reflexão acerca de suas condutas e atitudes na resolução de conflitos e negociação.

Recomendamos a inclusão da simulação como estratégia de ensino, devido a seu potencial para estimular a aprendizagem colaborativa e o desenvolvimento do pensamento crítico, voltados para o autoconhecimento e a melhoria do desempenho no âmbito profissional.

\section{Referências Bibliográficas}

ARAÚJO, A. L. L. S. \& QUILICI, A. P. "O Que É Simulação e Por Que Simular". In: QUILICI, A. P.; ABRÃO, K. \& TIMERMAN, Gutierrez F. Simulação Clínica: do Conceito à Aplicabilidade. São Paulo: Editora Atheneu, 2012.

BLAND, A. J.; TOPPING, A. \& WOOD, B. "A Concept Analysis of Simulation as a Learning Strategy in the Education of Undergraduate Nursing Students". Nurse Education Today, vol. 31, n. 7, pp. 664-667, 2011.

FIGUEIREDO, A. E. "Laboratório de Enfermagem: Estratégias Criativas de Simulações como Procedimento Pedagógico". Rev Enferm UFSM, vol. 4, n. 4, pp. 844-849, out./dez. 2014.

MEAKIM, C.; BOESE, T.; DECKER, S.; FRANKLIN, A. E.; GLOE, D.; LIOCE, L.; SANDO, C. R.; BORUM, J. C. "Standards of Best Practice: Simulation Standard I: Terminology". Clinical Simulation in Nursing, vol. 9, n. 65, pp. S3-S11, 2013.

OLIVEIRA, S. N.; PRADO, L. \& KEMPFER, S. S. "Utilização da Simulação no Ensino da Enfermagem: Revisão Integrativa". Rev Min Enferm., vol. 18, n. 2, pp. 487-49, 2014.

TEIXEIRA, I. \& FELIX, J. V. C. "Simulação como Estratégia de Ensino em Enfermagem: Revisão de Literatura". Interface [Botucatu], vol. 15, n. 39, pp. 117384, 2011.

VALADARES, A. F. M. \& MAGRO, M. C. S. "Opinião dos Estudantes de Enfermagem sobre a Simulação Realística e o Estágio Curricular em Cenário Hospitalar". Acta Paul. Enferm., vol. 27, n. 2, pp. 138-143, 2014.

Publicado em 30/06/2017. 